\title{
The IO-PS in the context of GVC-related policymaking: The case of the South African automotive industry
}

\author{
Wouter G. Bam ${ }^{1}$, Karolien De \\ Bruyne $^{2,1}$ and Mare Laing ${ }^{1}$ \\ ${ }^{1}$ Department of Industrial Engineering, \\ Stellenbosch University, Banghoek Street, \\ Stellenbosch 7600, South Africa; ${ }^{2}$ Faculty of \\ Economics and Business, KU Leuven, \\ Warmoesberg 26, 1000 Brussels, Belgium \\ Correspondence: \\ K Bruyne, Faculty of Economics and Business, \\ KU Leuven, Warmoesberg 26, 1000 Brussels, \\ Belgium \\ e-mail: karolien.debruyne@kuleuven.be
}

\begin{abstract}
Recent years have seen renewed interest in evaluating the effectiveness of industrial policy, especially in the context of global value chains. One approach that might add a complementary view in this domain is product space analysis. To date, product space-based value chain analyses have focused on theoretical debates only, or on empirical applications for a single year. In this paper, we employ the input-output product space (IO-PS) framework combined with a time dimension. We thereby evaluate the effectiveness of industrial policies within a value chain over time. The paper focuses on the case of the South African automotive value chain for the years 1995 to 2017. We evaluate ex post the implemented industrial policies and confirm their (partial) success. We then use the framework to make ex ante recommendations to improve the current policy approach and find that it might pay off to target specific sub-sectors in the future. The results illustrate how the framework can be used to evaluate industrial policies and to identify which parts of the global value chain should be targeted to foster both short- and long-term growth. We also highlight shortcomings of the approach which might limit its application.

Journal of International Business Policy (2021) 4, 410-432.

https://doi.org/ | 0.1057/s422/4-020-0008/-7
\end{abstract}

Keywords: global value chain analysis; product space; industrial policy; automotive industry; South Africa

The online version of this article is available Open Access

\section{INTRODUCTION}

Industrial policy has historically played a significant role in shaping international business patterns. For example, Gereffi (2014) describes the interplay of government policy and multinational corporation strategies through the periods of import-substituting industrialization, export-oriented industrialization, and what can be described as a "post-Washington Consensus World"1. More recently, industrial policy is again being viewed as key to promote innovation and growth in both developed and developing economies (Barnes \& Morris, 2008; Cimoli, Dosi, \& Stiglitz, 2009; Spring, Hughes, Mason, \& McCaffrey, 2017; Hausmann \& Rodrik,
Received: 30 August 2019

Revised: 25 September 2020

Accepted: 12 October 2020

Online publication date: 7 January 2021 
2006). Breaking from the Washington Consensus, there is an emerging view that governments need to drive structural development through targeted policy (Hausmann \& Rodrik, 2006; Horner, 2017). Yet, guidance for such policy has remained decidedly limited (Bam \& De Bruyne, 2019).

Within the context of the complex interplay between government action, international business strategy, and developmental outcomes, analytical frameworks such as the global production network (GPN) and global value chain (GVC) approaches have become increasingly important to a variety of stakeholders aiming to better understand new developments and to develop appropriate responses to emerging trends (Cheng, Farooq, \& Johansen, 2015; Coe \& Yeung, 2019). The GVC and GPN frameworks, in particular, have been adopted by development-oriented organizations to evaluate the impact of global value chains on host countries in terms of value capture and development, often framed in terms of local "upgrading" (Coe \& Yeung, 2019; Gereffi \& Lee, 2014; Li, Frederick, \& Gereffi, 2019). This highlights the particular strength of these frameworks. If a proper understanding of the GPN/GVC dynamics of a particular sector can be obtained, a (developing) country's government can be better equipped to define an effective industrial policy aimed at upgrading within an existing - or even entering a new - GPN/GVC. The increasing uptake of these frameworks has led to an increase in the explicit acknowledgment and inclusion of the role of the state in various contexts (Horner, 2017). Recent research has sought to strengthen the GPN framework's capacity, in particular, to support causal explanations between GPN configurations and development - with this updated framework referred to as GPN 2.0 (Coe \& Yeung, 2019).

Even though the evolving GVC and GPN frameworks are flexible analytical constructs, their intended use is largely descriptive/positivist and usually focused on one - or a limited number of sector(s) (Bam \& De Bruyne, 2017). This has meant that despite a myriad of studies focusing on the developmental outcomes in particular cases and understanding the underlying causes of these outcomes, these frameworks have not yielded, and not explicitly sought to provide, systematic guidance to governments in terms of their industrial policy strategies and the ideal process towards setting such policies. More in particular, various important questions regarding optimal policy regimes remain unanswered, leading governments to pursue intuitive but, at times, suboptimal policy strategies (Bam \& De Bruyne, 2019).

We argue that the capability theory-based inputoutput product space (IO-PS) approach proposed by Bam and De Bruyne (2019) has the potential to provide a much-needed additional perspective within the realm of value chain-based industrial policy. By considering the entire product space (PS), the IO-PS approach can efficiently consider the mutual strengthening capabilities between a large variety of industrial activities taking place within a region - by targeting one sector one might indeed unlock opportunities for other (related) sectors as well. Furthermore, the IO-PS approach can provide a predictive/normative evaluation of activities by estimating the potential impact on growth and capability development of the development of a particular activity. To date, the IO-PS has also been applied for a single year in order to derive suggestions for future policy direction.

In this paper, we critically investigate the ability of the IO-PS to support the evaluation of government policies in a given value chain over an extended time period. In particular, we perform a cross-sectional analysis of the IO-PS results for the South African automotive value chain. This enables a historical evaluation of the policies that the South African government have implemented. In particular, we evaluate the alignment of these policies with the theoretical results obtained from the IOPS and then first evaluate the success that these policies have achieved in general. In a next step, we analyze whether it might pay off to diversify the automotive policy to improve benefits attained in the future. The results provide insights relevant for both the particular case study as well as the future application of the IO-PS methodology for policy analysis within the context of global value chains.

The next section ("Background" section) provides the theoretical background to the study. This is followed by a section outlining the methodology applied in the execution of the research ("Methodology" section). The results from the application of this methodology, and the analysis of these results, are presented in the "Results and analysis" section. Finally, the "Conclusion" section concludes the paper by reflecting on the implications for policy in the case study country, and for the use of the IO-PS for the analysis of industrial policy more generally. 


\section{BACKGROUND}

This section provides the background to the paper by providing an overview of the PS and IO-PS ("The product space" section) and the automotive industry in South Africa ("The input-output product space approach" section) - being the case study we use in our analysis.

\section{The Product Space}

The product space studies the network of relatedness between products. An intuitive way to understand the product space is to imagine each product to be a single tree and the set of all products to be a forest (Hausmann \& Klinger, 2006). A country consists of a number of firms, which can be thought of as monkeys that live on the trees and exploit the products. The process of growth implies that the firms move from the poorest parts in the forest (trees bearing the least fruit) to the richest parts in the forest (trees bearing the most fruit) by simply redeploying the factors of production and gaining increasing capabilities. That implies that monkeys have to jump distances to get to other trees. If the forest were homogeneous, monkeys would be able to make any jump. However, in reality, we know that the forest is heterogeneous with some more dense areas and some less dense areas. Indeed, one could think of certain products that are located close together in the forest as they use similar factors of production - if a country for instance produces vehicles, it is likely to also be able to produce automotive-related parts. Other products will be located further away from one another. For instance, if a country produces cork, it does not imply it has the necessary factors of production to produce vehicles.

To capture this intuition, the product space makes use of the concept of proximity $\left(\phi_{i j}\right)$, which relies on the concept of revealed comparative advantage (RCA). The seminal work (Hidalgo et al., 2007) makes use of the Balassa (1965) definition to calculate an initial real RCA value. If we let $x(c, i)$ represent the exports of product $i$ from country $c$, this can be stated as (Hidalgo et al., 2007):

$$
\operatorname{RCA}_{c, i}=\frac{x(c, i)}{\sum_{i} x(c, i)} / \frac{\sum_{c} x(c, i)}{\sum_{c, i} x(c, i)}
$$

Using this calculation, a country $c$ can be said to "have an RCA" for a product $i$ (denoted as $x_{i}=1$ ) if the product constitutes a larger share of its export basket than for the average country i.e., $\mathrm{RCA}_{c, i}>1$. Otherwise, it can be said to "not have an RCA" for the product (hence $x_{i}=0$ ). The proximity of two products can then be calculated by evaluating the minimum pairwise probability that a country will "have an RCA" for both products. Mathematically, (Hidalgo et al., 2007):

$$
\phi_{i j}=\min \left\{P\left(x_{i} \mid x_{j}\right), P\left(x_{j} \mid x_{i}\right)\right\}
$$

The metric distance can then be used to express how proximate a particular "unobtained product" $j$ (a product with RCA $<1$ ) is in the product space to the collection of products which a country already exports "with an RCA" compared to all products in the product space. This can be expressed as (Hausmann et al., 2011):

$$
\Delta_{j}^{c}=\frac{\sum_{i}\left(1-x_{i}\right) \emptyset_{i j}}{\sum_{i} \emptyset_{i j}}(\text { for all } i \neq j)
$$

It can generally be expected that it will be easier for a country to obtain an RCA for an unobtained product with a lower distance value (Hausmann et al., 2011).

Further, it is possible to observe that the product space (or "forest" in the classic analogy) consists of a 'core' of more highly sophisticated products and a 'periphery' of less sophisticated products. Referring to capability theory, products in the periphery can be considered to require capabilities that do not enable the countries that produce them to produce many other products (Hidalgo \& Hausmann, 2009). For example, producing cork (located in the periphery of the product space) does not require capabilities that support the production of many other products. In contrast, competitively exporting vehicles (located in the core of the product space) is likely to lead to capabilities that could support the production of a variety of other products such as piston engines and automotive-related parts; laboratory-related equipment, or even boilers and related products - all products that have a relatively low distance to vehicles. In general, the core is formed by metal products, machinery and chemicals, while the periphery is formed by agricultural, fishing, mining, and extractive activities (Felipe, Kumar, Abdon, \& Bacate, 2012; Hidalgo \& Hausmann, 2009).

Some products require a combination of more complex capabilities in order to produce than simpler products. One might expect that less complex products can be produced by almost all 
countries, while more complex products can only be produced by the few countries that have acquired a combination of complex capabilities. Similarly, one might expect that countries with complex capabilities will be more diversified than countries that possess only a limited amount of sophisticated capabilities. Leveraging this intuition, Hidalgo and Hausmann (2009) introduced two indices. The first is the product complexity index (PCI), which ranks all exported products based on complexity of countries that exports each of the products with an RCA $>1$. The second is country economic complexity index (ECI), which ranks countries based on the complexity of the products each county exports with an RCA $>1$. These two metrics are interdependent and can be derived through the iterative "method of reflections" outlined in Hidalgo and Hausmann (2009).

Economic complexity reflects the amount of productive knowledge that is embedded in the productive structure of an economy. The more sophisticated products in the core (e.g., machinery and chemicals) have indeed a higher complexity than those in the periphery (e.g., mining and agriculture). Hausmann et al., (2011) illustrate that economic complexity can explain about $78 \%$ of the variation in income per capita across 128 countries. They moreover illustrate that economic complexity predicts future economic growth. Product complexity can thus provide crucial information to industrial policymaking aimed at supporting economic growth.

Returning to the analogy, not only is the product forest heterogeneous, it is also the case that the monkeys cannot jump any possible distance indeed firms are (financially/technically) limited in their options. That also implies that governments that want to stimulate their economy and/or their firms will have to invest more if the firms are initially located at the edge of the forest. Next to distance and complexity, the product space literature introduces a third important concept we will focus on, namely opportunity gain (Hausmann et al., 2011). If a monkey is able to reach a particular tree, reaching that tree might unlock opportunities to reach more and/or more sophisticated trees along the way. Defining those opportunity gain maximizing trees therefore is crucial as well to optimize the industrial policy.

More formally, the opportunity value $\left(\mathrm{OV}_{c}\right)$ of a country $c$ is the product of the complexity of all products $j$ for which the country does not have an RCA and the density of that country in terms of each product - where density $\left(\omega_{j}^{c}\right)$ is the proximity between all products for which a country has an RCA and product $j$ divided by the sum of the proximities between all products and product $j$. This can mathematically be expressed as:

$$
\mathrm{OV}_{c}=\sum_{j} \omega_{j}^{c} \mathrm{PCI}_{j} \text { where } \omega_{j}^{c}=\frac{\sum_{i} x_{i} \emptyset_{i j}}{\sum_{i} \emptyset_{i j}}(\text { for all } i \neq j)
$$

Opportunity gain then expresses how a country's opportunity value will change if it were to achieve an RCA for a product for which it does not yet have an RCA. A positive value will mean that by developing the capabilities to export the focal product, the country will reduce its distance to other high-complexity goods in the product space. This can then be expected to reduce the difficulty of developing the capabilities to produce these highcomplexity goods in the future. It thus gives an indication of whether the product lays the foundation for supporting economic growth opportunities in the longer run.

\section{The Input-output Product Space Approach}

The input-output product space (IO-PS) was introduced by Bam and De Bruyne (2019) who applied it to the case of the steel value chain in South Africa. It uses metrics developed in the product space literature for the analysis of value chains. In particular, Bam and De Bruyne (2019) focused on the interplay between the expected difficulty to achieve an RCA for a product or product group on the one hand (distance) and the preferred outcome (complexity and/or opportunity gain, respectively) on the other hand. They achieve this by means of a simulation that identifies the optimal development path of up to three product categories under different distance constraint scenarios.

The IO-PS framework starts by mapping the input-output structure of an industry. This is first mapped at a conceptual level, and then linked to international trade codes. A first outline is achieved by making use of input-output tables and concordance tables from these input-output tables to trade codes. These mappings are then further refined by logically arranging the trade codes identified into different product categories and tiers. The product categories are based on the premise that the trade codes that are combined in a category will be produced by the same firms and/ or will be targeted by the same interventions. The product categories are broadly arranged into tiers based on the typical input-output relations 
between these categories. Although input-output tables provide an initial starting point for relevant trade code identification, they are usually at too high a level of granularity to be solely relied upon. The trade codes that are included - and their allocation to product categories and tiers - in the final mapping thus require a more nuanced understanding of the industry under evaluation. Hence, apart from extensive desktop research to inform the final mapping, uncertainties can be settled through discussions with industry practitioners to ensure the mapping reflects the reality within the industry value chain (Bam \& De Bruyne, 2019).

The IO-PS calculates the PS metrics as normal, but then overlays the results on the value chain at the product level and aggregates the results at the product category ${ }^{2}$ and tier level of the value chain. This value chain perspective on the PS metrics can provide a more intuitive and, arguably, much more compelling, input to industrial policy decisionmaking - particularly in the case of industry specific industrial policymaking - than the traditional PS approach. The logical structuring of the products according to input-output relations also ensures that the results can be more directly linked to more in-depth second-stage evaluations, such as GVC/GPN analysis and other follow-on industryspecific studies.

Apart from a static evaluation of the various metrics, Bam and De Bruyne (2019) also perform a dynamic analysis of optimal development paths for different distance scenarios that either maximize complexity or opportunity gain. These different distance scenarios enable the evaluation of the different policy options available to a country. For example, a country can opt for a developmental path mainly aimed at supporting activities that are closely related to its existing production structure, or rather a more ambitious (and likely more expensive) industrial policy that seeks to develop sophisticated new capabilities that can drive accelerated growth in the future.

\section{Empirical Applications of the Product Space}

Numerous studies have sought to empirically apply the product space. The goal of this section is to provide an overview of those studies that are relevant to frame our empirical analysis, without being exhaustive in our discussion. These studies broadly employ similar metrics as outlined above or make use of precursors to these metrics, e.g., EXPY and PRODY instead of ECI and PCI, respectively (e.g., Hausmann \& Klinger, 2008). Such studies generally range from being applied to a broad range of countries to explore or improve the general application and interpretation of metrics (e.g., Fortunato, Piergiuseppe, Razo, Carlos and Vrolijk, 2015) to focusing on a particular region (e.g., Abdon \& Felipe, 2011) or country (e.g., Vardhana Singh, Gupta, Sudan, \& Singh, 2018) to derive practical policy advice. The more recent IO-PS approach developed by Bam and De Bruyne (2019) provides a way to leverage these metrics within a more focused industry-specific and value chainoriented analysis. As a follow on to this study, Marais and Bam (2019) have also applied the IO-PS methodology to the case of the aerospace industry. Yet apart from these two studies, the application of the IO-PS is still in its infancy.

The level of analysis chosen by each study has far-reaching implications for the type of insight that the study delivers. Undoubtedly, multiple country studies will remain critical to the further theoretical development of the product space and its underlying metrics. At the same time, the ever more focused application of these metrics is needed to better support targeted industrial policy decision-making and much scholarship still seems necessary to improve the informed integration of these metrics into policy-making processes. Indeed, before such an integration can be advised, its benefits and limits must be very well understood. As such, we next review the shortcomings of the product space and IO-PS approach in particular.

\section{Shortcomings of the Input-output Product Space Approach}

The IO-PS is broadly exposed to the same shortcomings as the product space on which it is based. In particular, the product space uses a heuristic method for calculating the complexity of products. It does not directly measure the capabilities that underlie the production of products but aims to estimate the existence and complexity of these capabilities based on trade patterns. This estimation is not precise, and some differences invariably occur depending on which data sets are used or which year's trade data are employed. Nonetheless, the methodology's results have been shown to be predictors of economic growth (Hidalgo \& Hausmann, 2009). The complexity values thus have very real value for policy-making but must be interpreted with caution.

Another shortcoming that arises due to the product space's reliance on the data of 1 year is that it does not consider the trends for any 
particular industry, i.e., it might suggest that a country should target the production of internal combustion engines, even though the market demand for such engines might be declining. Furthermore, the IO-PS framework might suggest tackling a particular sector in the host country not to be difficult, as countries with similar production structures have been able to support the focal industry. However, there could be particular circumstances within the focal country that preclude the successful development of the industry, such as geopolitical considerations or other unique features that are particular to the country and sector, but do not affect other related industries.

The IO-PS framework also does not provide insight regarding the particular drivers of competitiveness for a particular product or industry. It thus does not support answering "how" a particular industry might be targeted by means of industrial policy. In order to tackle these shortcomings, case study analyses would be required to follow the IOPS analysis in order to validate the quantitative findings in terms of desirable (and easy to acquire) industries and to provide insight regarding how a particular industry might best be targeted. Such feasibility studies will then be able to more accurately assess what the expected benefits, cost, and difficulty of attaining a competitive position in the value chain would be. During this stage, various concepts from the GVC and GPN literature will be of significant importance. This includes aspects such as the power relations between different actors and the rents that would accrue to the various stakeholders.

Despite these shortcomings, the main advantage of product space-based approaches is their ability to very rapidly assess and compare different industrial activities and industries in terms of their expected contribution towards the development of capabilities that can support long-term economic growth within a country. It also provides an indication of how easy it might be for a country to develop the ability to competitively export a specific product given the current products that it already exports. The IO-PS harnesses these features and focuses the analysis on a particular value chain. It will therefore allow us to immediately generate an overview of those product categories within the automotive value chain that are worth a deeper analysis. Further case studies for the different selected product categories can then in a second stage provide a better insight into the potential of these categories
- given both the required investments as well as their feasibility.

\section{South Africa as a Suitable Case for Evaluation}

When selecting a case for the purposes of this study, we considered a number of aspects. As we seek to evaluate the ability of the IO-PS to support industrial policy analysis, it was important to consider when this approach is most applicable. The IO-PS analysis becomes more relevant when a country has at least some industrialization and diversification, as this provides a foundation of capabilities which can be harnessed to develop an increasing number of related activities. At the same time, a country should still be classified as developing or emerging, in order to ensure that there are still parts of the product space that remain undeveloped and can be targeted by the focal country. This is because the IO-PS does not consider how the product space changes over time, but relies on the targeting of the product space as it is - whereas highly developed countries might be more interested in evaluating how the product space will be changing in the near future and driving this change through advanced research and development. The IO-PS will thus be a more relevant analysis tool when a middle-income country that has a moderate level of development is seeking to improve its industrial policy targeting to better achieve its developmental goals. This might be particularly true in the case of countries that might be classified as having fallen into the so-called "middle-income trap". These countries seem to stagnate and need to refocus their developmental paths to ensure continued growth. An increasing number of studies are thus seeking to use the product space to analyze the phenomenon of the middle-income trap (Hartmann, Bezerra, Lodolo, \& Pinheiro, 2019; Jankowska, Nagengast, \& Perea, 2012).

Given the above, South Africa is an interesting case as a country caught in the "upper middleincome trap" (Lavopa \& Szirmai, 2018). Furthermore, the government is, and has for the past decades been, experimenting with a variety of policy mixes and interventions in order to support growth in a variety of industries. Yet the country has, particularly more recently, experienced disappointing levels of growth. South Africa's industrial policies thus seem to be of increasing importance, with various barriers that are hindering "automatic" further growth. Indeed, South Africa's government has been undertaking a significant number of industrial policies to facilitate its 
industrial development though some end results were not as positive as expected.

\section{The Automotive Industry in South Africa}

Within the context of South Africa, the automotive industry is a particularly relevant value chain to study. First and foremost, it is South Africa's most important manufacturing sector. Approximately one-third of value added within the domestic manufacturing sector is derived either directly or indirectly from vehicle assembly and automotive component manufacturing activity, making it responsible for $2-3.5 \%$ of total employment ${ }^{3}$ (Barnes, Black, Comrie, \& Hartogh, 2018). Moreover, it is the fourth largest exporting sector of the country after gold, diamonds, and platinum (OEC, 2019) and South Africa accounts for approximately $45 \%$ of the total African car production. In 2018, 610,854 new vehicles (passenger cars and commercial vehicles) were produced in South Africa, 402,085 in Morocco, and 71,600 in Egypt (www. oica.net).

Secondly, and unsurprisingly, it is one of the 16 priority sectors that the Department of Trade and Industry (DTI) National Industrial Strategy identifies ${ }^{4}$. The South African government has indeed provided substantial support for the automotive industry in the past 20 years - with albeit varying effectiveness - and is still identifying it as a key growth sector. In a DTI Budget Vote Address delivered in July 2014, Trade Minister Rob Davies said that "Given that automotives comprise 30\% of our industrial sector with strong linkages to other manufacturing sub-sectors, the impact of such investment on our domestic economy is significant" (Department: Trade and Industry, 2014). The Department of Trade and Industry has provided a series of programs in order to assist the sector. The first of the programs - the Motor Industry Development Programme (MIDP) - was introduced in 1995. Under the MIDP, the sector was confronted with a widening trade deficit as imports grew faster than exports. Production increased, but so did imports of original equipment components, lowering the local content of production (Black \& Bhanisi, 2007). Hence, the picture regarding the effectiveness of the MIDP is mixed. Its successor, the Automotive Production and Development Programme (APDP), was implemented on January 1, 2013. The APDP's main goal has been to simultaneously stimulate the expansion of local production to 1.2 million vehicles a year by 2020 and increase significantly the local content of these vehicles (South African Government, 2015). The intention has been to achieve this through investments, unlike the MIDP which relied mainly on exports.

In South Africa, foreign direct investment (FDI) is driven by the interplay between industry-based 'market-seeking' and 'efficiency-seeking' (dis)advantages (Dunning, 1998). South Africa's automotive policy has been aimed at enhancing both market access and efficiency for potential investors by simultaneously allowing for cuts on import duties and stimulating exports. Two important critiques are however often raised against this support for the automotive industry. First, it is said to cause higher prices for domestic consumers, and second, it is argued that local content requirements are not high enough, thus not stimulating the local economy sufficiently.

Both the MIDP and the APDP are broad-based policies that target the automotive industry in general rather than particular sub-sectors directly. According to APDP regulations, all final manufacturers based in South Africa, which are registered with the South African Revenue Service (SARS) as taxpayers, can apply for Production Rebate Credit Certificates (PRCC). The eligible products are (i) specified motor vehicles fitted with an engine and gearbox manufactured in a licensed, special vehicle manufacturing warehouse in South Africa; (ii) specified motor vehicles not fitted with an engine or gearbox manufactured in a licensed, special vehicle manufacturing warehouse in South Africa; (iii) automotive components applicable to specified motor vehicles; (iv) automotive tooling; and (v) automotive components applicable to heavy motor vehicles. All firms producing these goods are entitled to PRCC, which implies they get cuts on the import duties on components and vehicles.

In recognition of the central importance of the domestic automotive industry for the future growth of the South African economy, the DTI commissioned in 2016 the development of the South African Automotive Masterplan project 2035. The report was completed in November 2018 and although it is purely intentional, it is meant to provide the foundation on which the country's post-2020 policy is created (Barnes et al., 2018). Crucial in the report are enhancing global competitiveness, industry transformation, sustainable development, and societal contribution. These four objectives are translated into six very concrete and ambitious goals, namely (i) increase production to $1 \%$ of global output, (ii) increase local content to 
up to $60 \%{ }^{5}$, (iii) double employment, (iv) improve competitiveness levels to that of leading international competitors, (v) transformation of the industry through e.g., employment of black South Africans, and (vi) deepen value addition within value chains.

\section{METHODOLOGY}

We seek to evaluate the application of the IO-PS for industrial policy analysis. In so doing, we also aim to provide a new perspective on the automotive industry in South Africa and the policy choices that have been made to support the industry. To achieve this, we apply the IO-PS framework to the industry at two time periods, namely 1995 and 2017. The former is chosen as a baseline year at the start of the modern era of intervention in the country, namely right before the MIDP and APDP. The latter is chosen as the most recent period for which comprehensive data were available. This provides us with a long enough time period to be able to expect the implemented policies to have had an influence on industry outcomes. However, such a crosssectional design does have a variety of potential pitfalls, which should be considered during interpretation. One such pitfall is that the specific years that are evaluated are outliers and not representative of the general trend over the period analyzed. To address this, we evaluated the values of key metrics for the intervening years to ensure that the two chosen years are not clear outliers and are in line with the general trends over this period (see "Appendix") ${ }^{6}$.

As a first step of the IO-PS analysis, we map the automotive industry value chain in a similar manner to how Bam and De Bruyne (2019) mapped the steel industry. In particular, we used the 2002 Make and Use Tables published by the US Bureau of Economic Analysis to identify the key relations between activities within the value chain. The 'Make and Use tables' as such allow us to define which products are used to make other products. More in particular, the categories are divided into tiers based on their input-output relations. Thus, tier $\mathrm{n}$ category products consume products in tier $n-1$ during production. Secondly, we convert the key identified activities to six-digit harmonized system (HS), revision 1992, trade codes using concordance tables. These trade codes are then arranged according to their input-output relations and grouped in logical categories according to which products can be expected to be produced by the same industry players and which can be targeted together. The resulting mapping was further refined by discussing it with a number of stakeholders, including individuals in senior roles in automotive vehicle production companies and government institutions responsible for implementing policies to support the industry. The goal of these validation discussions was to ensure that no critical trade codes were excluded from the mapping and that trade code arrangement into categories and tiers reflected practical reality. Once satisfied with the value chain mapping, trade data for the 2 years of interest were downloaded from the OEC website (OEC, 2020a).

Using this data, we calculate five metrics that we ultimately focus on to evaluate the effectiveness of South Africa's automotive industry. The first variable is RCA of South Africa in the automotive sector with respect to the rest of the world. Following the precedent in the literature, we use the definition of Balassa (1965) presented in the "Background" section. A second variable is the direct ratio of South African exports to world exports. Especially from a dynamic point of view, it is important to evaluate how this variable has changed since the introduction of the MIDP and APDP. The third metric used is distance, as defined in the "Background" section. If a country has a large distance to some product $j$, this implies that it does not have an RCA in many of the proximate products to product $j$ and it could be expected that it would be more difficult to acquire an RCA for it than for some product with a smaller distance value (Hausmann et al., 2011). As a fourth metric, we evaluate the product complexity index (defined in the "Background" section) using the method of reflections (Hidalgo \& Hausmann, 2009), aggregated at the product category and tier level. Generally speaking, the more complex the products, the more likely they are to contribute to the growth (potential) of a country if it is able to develop the ability to export these products with a revealed comparative advantage. The last metric is the opportunity gain of a product (defined in the "Background" section). A high opportunity value of a country implies that the products with low distances for that country generally have high complexity values.

In our Results section, we rely on the first two metrics to evaluate the general effectiveness of the South African automotive policy over time (19952017) while we will build on the last three metrics to discuss how the policy might possibly be further fine-tuned. 


\section{RESULTS AND ANALYSIS}

This section presents and discusses the results from the application of the IO-PS to the chosen case study. The discussion focusses on the results for the generic automotive value chain ("Generic automotive value chain" section), the evaluation of the changes in the industry in South Africa since 1995 ("The automotive industrial policy: general evaluation" section) and what the results suggest for the future targeting of the automotive industry in South Africa ("The automotive industrial policy: optimal future fine-tuning using the IO-PS" section). Finally, the "Discussion of implication of results" section provides a discussion of the results, with a reflection of the implications for the case study, as well as the application of the IO-PS more generally.

\section{Generic Automotive Value Chain}

Before being able to evaluate South Africa's automotive industrial policy, it is necessary to have an understanding of the generic automotive value chain. Figure 1 illustrates the generic automotive value chain, along with the global complexity scores for each Product Category and Tier in 2017 - the most recent year for which data is available. The Tier 3 suppliers (Components, minor parts/ assemblies) provide inputs for the Tier 2 suppliers (Sub-assemblies, major parts) who themselves provide the inputs for the Tier 1 producers (final assembly). Below each Tier, there is a detailed overview of the different Product Categories that can be categorized under the Tier considered. In Fig. 1 and throughout the remainder of the text, we use a color scaling to ease the interpretation of results. In each case, the values are colored on a spectrum ranging from red (least desirable from the perspective of a government seeking to intervene in industry), orange over yellow to green (most desirable) ${ }^{7}$.

On average, the Tier 3 products have a lower complexity than the products in the Tier 2 category
Figure 1 Automotive value chain with color-coded average complexity values for 2017.

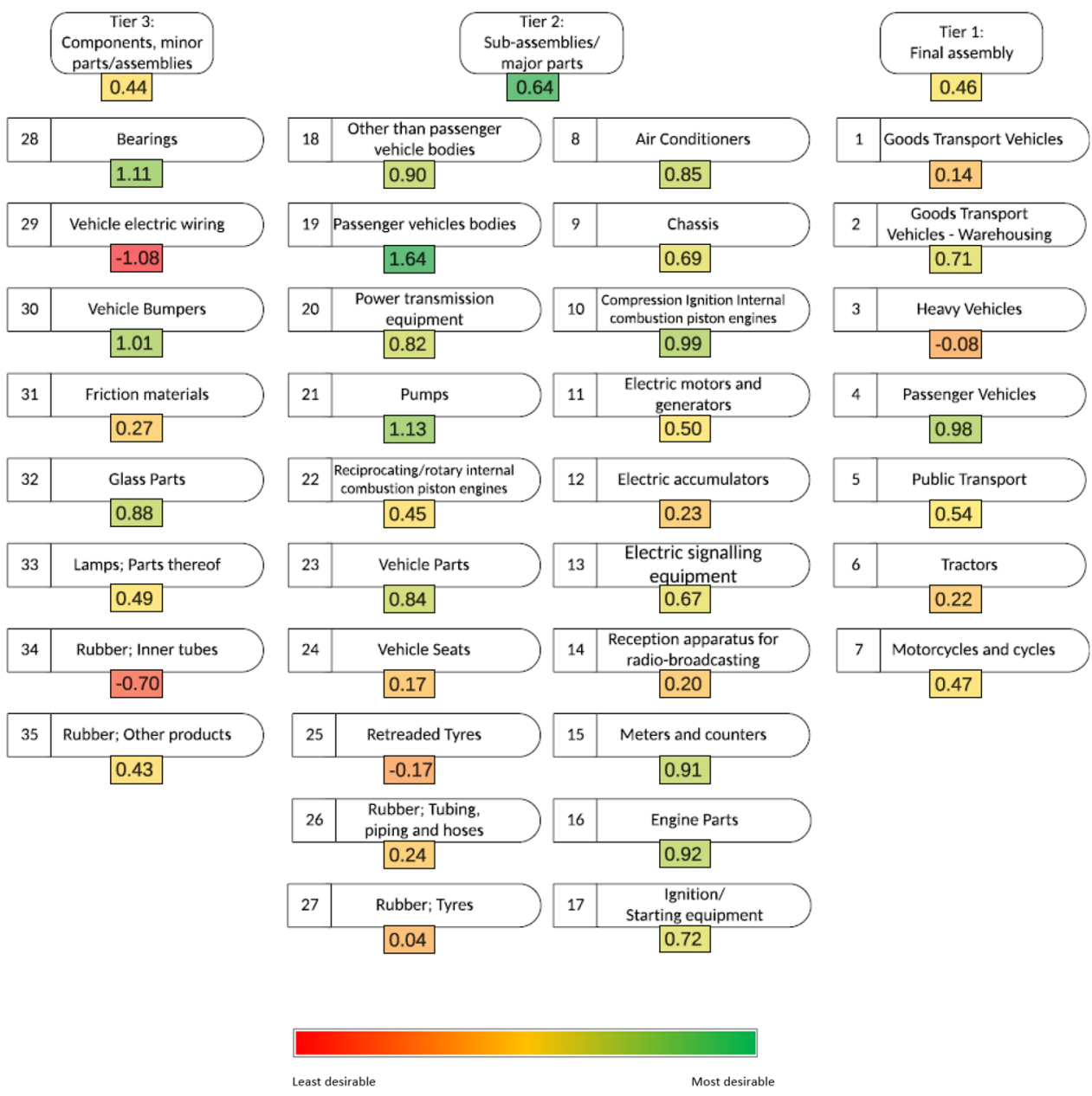


- for which they are used as inputs. The Tier 2 products on average reveal a higher complexity than either the Tier 1 or Tier 3 products, highlighting the importance of attaining a revealed comparative advantage in these products and the potential they hold for (short term) development. However, drawing conclusions by merely considering a Tier level analysis can be misleading. Indeed, at the Product Category level, large differences can be observed. Within Tier 2, Product Category 19 (Passenger Vehicles Bodies) has a higher complexity value than any Product Category under Tier 1 . Within Tier 3, Product Category 28 (Bearings) has a higher complexity than almost all Product Categories in Tier 2.

\section{The Automotive Industrial Policy: General Evaluation}

In our analysis of the automotive industrial policy, we specifically focus on the development of the automotive industry in South Africa since 1995. This marks the modern era of government support of the automotive industry. In particular, the MIDP stretched from 1995 to 2012. This was followed up by the APDP, which was introduced in 2013, with minor changes implemented in 2016. We thus perform a cross-sectional analysis focusing on the year 1995 (as a baseline before any of the programs were implemented) and 2017 - the most recent year for which data are available in our trade data set. In particular, we evaluate the total value of exports of products linked to each part of the value chain, along with the revealed comparative advantage of each part of the value chain. This provides an indication of how effective government intervention has been and which activities (if any) in the value chain have benefited. Note that both the MIDP and the APDP are broad-based policies that target the automotive industry in general rather than particular sub-sectors directly. The goal of this subsection is therefore to determine which subsectors mainly thrived under these broad-based industrial policies.

Table 1 contains the South African and World Exports in 1995 and 2017 (in million USD). The last column of the table illustrates the ratio of growth (SA to the world). South Africa has outperformed growth in industry for almost all related subsectors; especially for passenger vehicles, goods transport vehicles, compression ignition internal combustion piston engines and retreaded tires. This provides us with a first indication of the possible success of the automotive industrial policy. Based on these export data, one could tentatively conclude that the automotive industrial policy was a success. Indeed, as is obvious from Fig. A.1 in the Appendix, on average, the ratio of South African exports over world exports increases for most product categories throughout the years 19952017, except for a few cases. This also implies that 1995 and 2017 are not considered outliers and we can safely compare these 2 years in our analysis. However, by simply analyzing the data on exports one cannot draw any strong conclusions on the effectiveness of the broad-based automotive policy. Firstly, these results could (partially) be attributed to a simple 'catch-up' effect stating that developing economies grow faster simply because they have to catch up with the more developed countries. On the other hand, since South Africa is an upper middle-income country (World Bank, 2019), this argument might be less convincing. Secondly, while the export data paint a clear positive picture, this is less so for the data on revealed comparative advantage (RCA). The export data are expressed in absolute terms and therefore paint a partial picture while the RCA data are by definition of a comparative nature and thus more encompassing.

Since an interpretation of the export data as such can cause a biased evaluation of the automotive industrial policy, we focus on RCA in the different product categories as well. Figure 2 indeed reveals that RCA has not improved for all product categories simultaneously. In Fig. 2, one observes two rectangles below each product category. The lefthand side rectangle illustrates RCA for 1995 while the right-hand side rectangle illustrates RCA for 2017. We follow the same color coding as in Fig. 1. For about half of the categories, we observe an increase in RCA while the other categories are confronted with a decrease. Positive 'outliers' are passenger vehicles, goods transport vehicles, compression ignition internal combustion piston engines, meters and counters, goods transport vehicles, retreaded tires, and heavy vehicles. Negative outliers on the other hand are passenger vehicle bodies, bearings, vehicle bumpers, vehicle seats, vehicle electric wiring, and rubber and inner tubes. It would, however, be reassuring if the positive outliers were sub-sectors with a relatively high complexity while the sub-sectors that showed a decreasing RCA were characterized by a lower complexity. We therefore linked the RCA evolution of the sub-sectors to their respective complexities. Three of the highest complexity sub-sectors saw an increase in their RCA (sub-sectors 4, 10, and 15), 
Table 1 South African and world exports in 1995 and 2017 (in millions of USD)

\begin{tabular}{|c|c|c|c|c|c|c|c|c|}
\hline \# & Description & $\begin{array}{l}\text { SA } \\
\text { export, } \\
1995\end{array}$ & $\begin{array}{l}\text { SA } \\
\text { export, } \\
2017\end{array}$ & $\begin{array}{l}\text { Average } \\
\text { annual } \\
\text { growth } \\
(\%)\end{array}$ & $\begin{array}{l}\text { World } \\
\text { export, } \\
1995\end{array}$ & $\begin{array}{l}\text { World } \\
\text { export, } \\
2017\end{array}$ & $\begin{array}{l}\text { Average } \\
\text { annual } \\
\text { growth } \\
(\%)\end{array}$ & $\begin{array}{l}\text { Ratio of } \\
\text { growth } \\
\text { (SA to } \\
\text { world) }\end{array}$ \\
\hline 1 & Goods transport vehicles & 95.8 & 2227.6 & 15.4 & $42,564.1$ & $135,698.5$ & 5.4 & 10.2 \\
\hline 2 & Goods transport vehicles-warehousing & 0.1 & 3.5 & 18.1 & 340.3 & 1182.5 & 5.8 & 15.3 \\
\hline 3 & Heavy vehicles & 3.0 & 27.7 & 10.7 & 3301.2 & $11,551.9$ & 5.9 & 3.3 \\
\hline 4 & Passenger vehicles & 137.0 & 6903.4 & 19.5 & $233,743.4$ & $746,682.1$ & 5.4 & 22.5 \\
\hline 5 & Public transport & 16.1 & 23.3 & 1.7 & 5314.0 & $16,793.3$ & 5.4 & 0.2 \\
\hline 6 & Tractors & 12.6 & 105.8 & 10.1 & $19,518.0$ & $48,972.2$ & 4.3 & 4.9 \\
\hline 7 & Motorcycles and cycles & 2.1 & 15.0 & 9.3 & $10,986.0$ & $31,710.6$ & 4.9 & 3.2 \\
\hline 8 & Air conditioners & 7.4 & 47.1 & 8.8 & $13,461.8$ & $48,046.0$ & 6.0 & 2.1 \\
\hline 9 & Chassis & 0.8 & 1.3 & 2.1 & 2641.4 & 3883.5 & 1.8 & 1.2 \\
\hline 10 & $\begin{array}{l}\text { Compression ignition internal combustion } \\
\text { piston engines }\end{array}$ & 1.3 & 75.7 & 20.1 & $10,338.3$ & $43,817.9$ & 6.8 & 17.1 \\
\hline 11 & Electric motors and generators & 0.3 & 4.7 & 13.0 & 485.8 & 1513.0 & 5.3 & 6.4 \\
\hline 12 & Electric accumulators & 16.4 & 37.7 & 3.9 & 7779.0 & $42,463.1$ & 8.0 & 0.3 \\
\hline 13 & Electric signaling equipment & 1.0 & 16.6 & 13.9 & 4169.8 & $28,979.9$ & 9.2 & 2.7 \\
\hline 14 & Reception apparatus for radio-broadcasting & 0.4 & 1.2 & 4.8 & 8031.3 & 9566.8 & 0.8 & 9.3 \\
\hline 15 & Meters and counters & 0.6 & 8.6 & 12.9 & 1998.8 & 8302.3 & 6.7 & 4.2 \\
\hline 16 & Engine parts & 35.9 & 275.8 & 9.7 & $22,832.6$ & $74,445.9$ & 5.5 & 3.0 \\
\hline 17 & Ignition/starting equipment & 4.9 & 18.8 & 6.3 & 6530.0 & $19,771.8$ & 5.2 & 1.4 \\
\hline 18 & Other than passenger vehicle bodies & 1.2 & 2.8 & 3.9 & 1832.2 & 4955.8 & 4.6 & 0.8 \\
\hline 19 & Passenger vehicle bodies & 0.5 & 5.6 & 11.7 & 536.0 & 3478.3 & 8.9 & 1.9 \\
\hline 20 & Power transmission equipment & 0.3 & 1.7 & 8.9 & 757.7 & 1766.9 & 3.9 & 4.1 \\
\hline 21 & Pumps & 7.5 & 113.6 & 13.1 & 8225.0 & $28,819.6$ & 5.9 & 5.6 \\
\hline 22 & $\begin{array}{l}\text { Reciprocating/rotary internal combustion } \\
\text { piston engines }\end{array}$ & 0.6 & 127.1 & 27.5 & 17948.1 & $35,692.5$ & 3.2 & 212.7 \\
\hline 23 & Vehicle parts & 275.4 & 2043.1 & 9.5 & $95,222.4$ & $397,456.5$ & 6.7 & 2.0 \\
\hline 24 & Vehicle seats & 227.0 & 52.4 & -6.4 & 5102.4 & $34,398.8$ & 9.1 & -0.1 \\
\hline 25 & Retreaded tires & 0.1 & 1.9 & 16.4 & 288.5 & 666.6 & 3.9 & 21.0 \\
\hline 26 & $\begin{array}{l}\text { Rubber: vulcanized: tubing, piping and hoses, } \\
\text { with fittings }\end{array}$ & 1.0 & 11.3 & 11.8 & 1000.1 & 4290.9 & 6.8 & 3.2 \\
\hline 27 & Rubber: new pneumatic tires & 39.3 & 170.8 & 6.9 & $18,504.7$ & $65,394.4$ & 5.9 & 1.3 \\
\hline 28 & Bearings & 12.6 & 31.3 & 4.2 & $10,657.7$ & $28,445.6$ & 4.6 & 0.9 \\
\hline 29 & Vehicle electric wiring & 10.9 & 13.2 & 0.9 & 6716.4 & $35,776.3$ & 7.9 & 0.0 \\
\hline 30 & Vehicle bumpers & 5.5 & 28.4 & 7.8 & 1404.6 & 7152.0 & 7.7 & 1.0 \\
\hline 31 & Friction materials & 1.5 & 3.0 & 3.2 & 633.4 & 1420.9 & 3.7 & 0.8 \\
\hline 32 & Glass parts for vehicles & 16.1 & 32.4 & 3.2 & 3038.3 & $10,633.0$ & 5.9 & 0.4 \\
\hline 33 & Lamps; parts thereof & 0.5 & 1.9 & 6.1 & 1576.7 & 2669.7 & 2.4 & 3.8 \\
\hline 34 & Rubber: inner tubes & 1.3 & 0.8 & -1.8 & 672.0 & 1030.3 & 2.0 & -0.6 \\
\hline \multirow[t]{2}{*}{35} & $\begin{array}{l}\text { Rubber: gaskets and other vulcanized articles } \\
\text { n.e.s. }\end{array}$ & 3.3 & 30.0 & 10.6 & 5810.4 & $24,072.2$ & 6.7 & 2.6 \\
\hline & Total & 940.1 & $12,465.1$ & 12.5 & $573,962.5$ & $1,961,501.5$ & 5.7 & 5.1 \\
\hline
\end{tabular}

but three others were confronted with a decrease in their RCA (sub-sectors 19, 28, and 30). Likewise, for three of the sub-sectors with the lowest complexity we observed a decrease in their RCA (sub-sectors 24, 29, and 34), while for three others we saw an increase in their RCA (sub-sectors 1, 3, and 25). Overall, the correlation coefficient between an increase in RCA and the complexity of a sub-sector was calculated to be 0.16 , which indicates that it is definitely not always the most complex sub-sectors that ultimately witnessed an increase in their RCA. Our positive overall evaluation of the broad-based automotive industrial policy based on the export data is therefore only partially confirmed when 
Figure 2 RCA for South Africa in the automotive industry in 1995 and 2017.

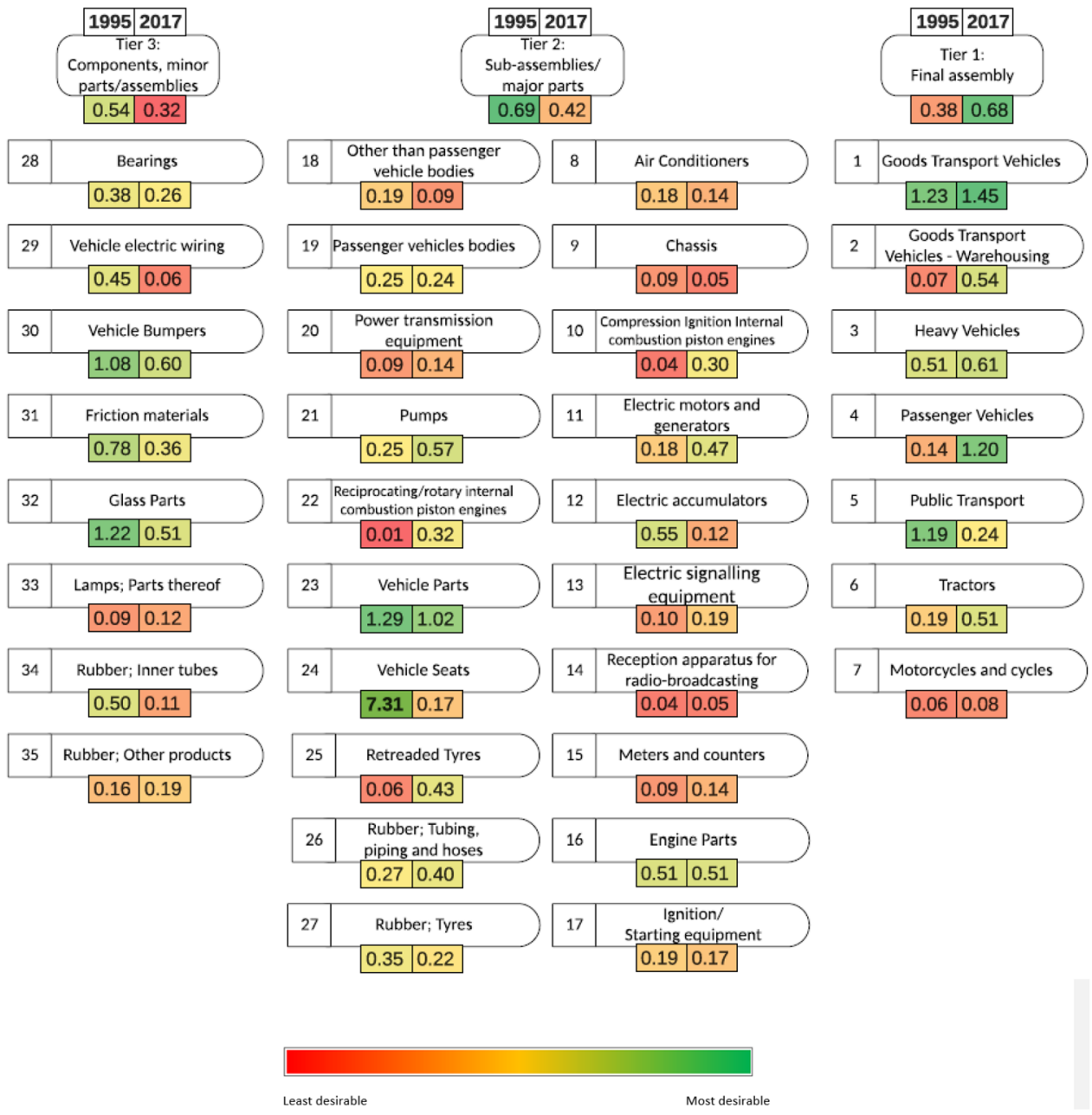

considering the RCAs of the different sub-sectors. It is possible that several sub-sectors have benefited from the MIPD and APDP but this is definitely not the case overall. Figure A.2 in the Appendix confirms this finding: throughout the years 1995 to 2017, some product categories witnessed an increase in RCA while for other product categories RCA has decreased. The years 1995 and 2017 are again no outliers, rendering their comparison valid.

The discrepancy between the RCA and the absolute export values can be further explored by considering the export basket for South Africa for the 2 years under evaluation. These are compared in Fig. 3. The figure clearly shows the increasing importance of the automotive industry in South Africa, driven primarily by the increased export of cars. It also indicates a dramatic increase in total exports (from $\$ 16.6 \mathrm{~B}$ in 1995 to $\$ 108 \mathrm{~B}$ in 2017). Another striking change is the significant increase in the export of precious minerals and stones - in particular diamonds and platinum. The large increases in the exports of these commodities effectively dilute the contribution of all other sectors (including the automotive industry) to the export basket, contributing to the RCA value not reflecting the dramatic growth in the car industry to the extent that may be expected.

The question therefore remains whether the policy can be further optimized in the future. More in particular, we apply the full IO/PS framework to the automotive industry to determine which subsectors appear the most promising from both a complexity maximizing point of view and an opportunity gain maximizing point of view. For the short-run case, we assume that the government is mainly focused on generating output and employment and therefore aims at maximizing complexity of the selected sub-sector(s). In the longer run, we assume the government not only takes the complexity of the targeted sub-sector 
Figure 3 Export basket of South Africa in 1995 and 2017, downloaded from OEC (2020b).

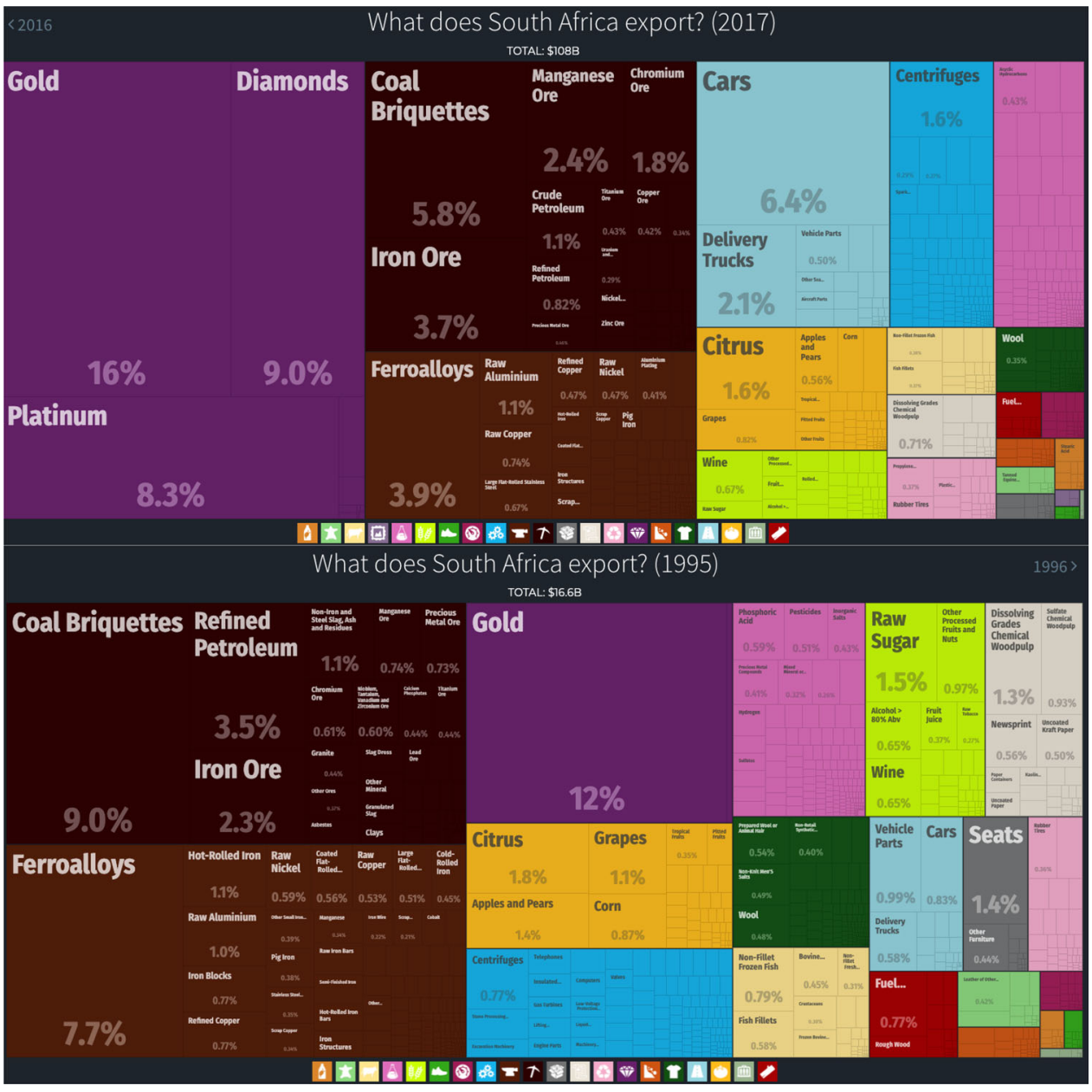

their budgetary constraint(s). We now tackle these shortcomings and as such try to determine whether it would appear to make sense to 'diversify' the current broad-based automotive industrial policy in the future by focusing the policy on the most 'promising' sub-sectors. Before moving to the dynamic analysis, we first have a look at the average complexity and opportunity gain values of the products within each category/tier for which South Africa does not yet have an RCA (Fig. 4). The left-hand rectangle under each product category illustrates the complexity value while the righthand side rectangle illustrates the opportunity gain. The colors range on the same spectrum from red (least desirable) over orange and yellow to green (most desirable). The first interesting aspect to notice is that some sub-sectors appear more promising than others. The second important - and reassuring - element to notice is that most of the time the complexity and opportunity gain values move in the same direction: a sub-sector that 
Figure 4 Average complexity and opportunity gain values of the products within each category/tier for which South Africa does not yet have an RCA.

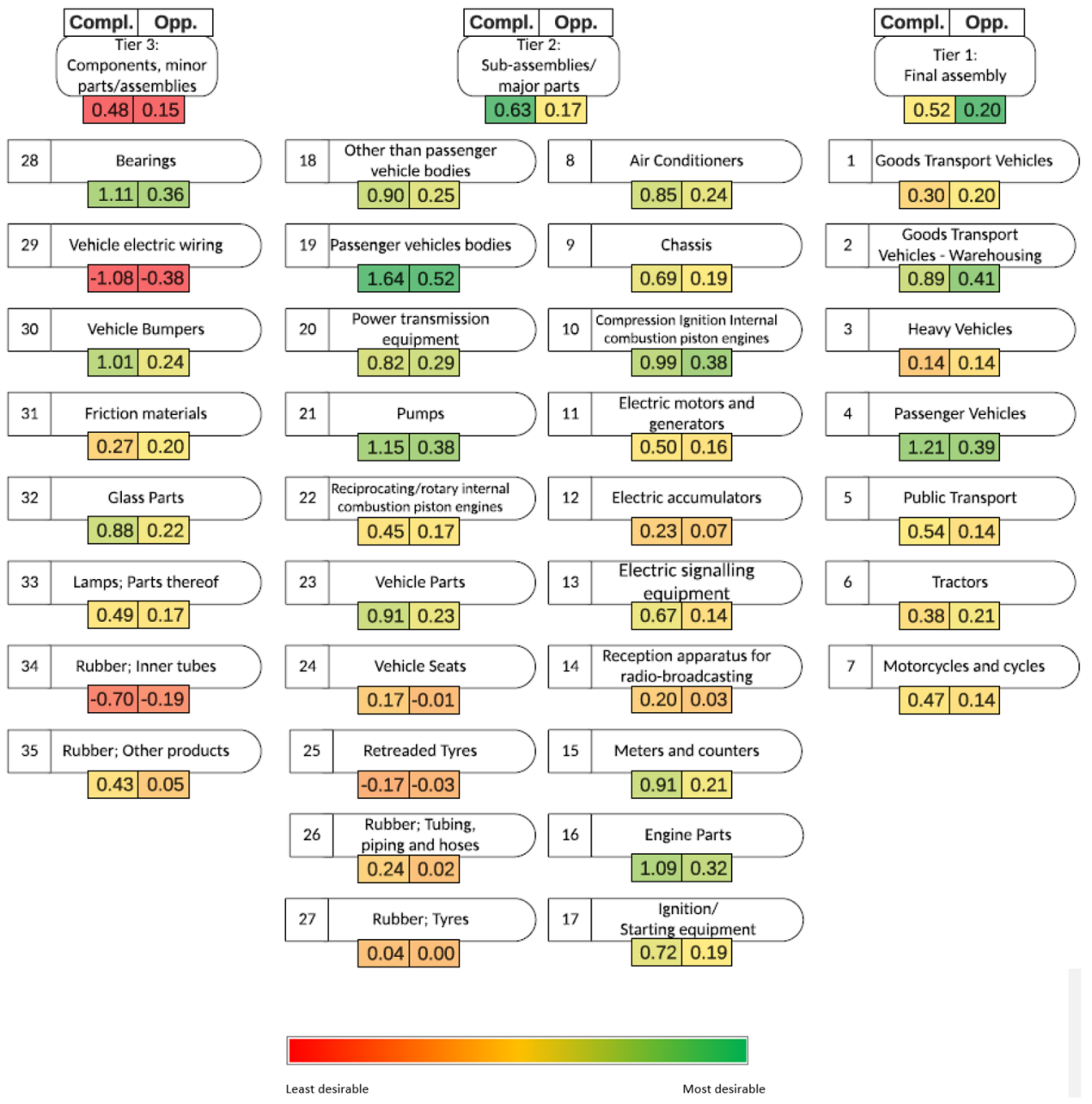

'scores' high as far as complexity is concerned, on average scores high as well on opportunity gain value. Figure 4, however, does not provide any insight into how easy or difficult it might be to attain an RCA in a certain sub-sector. In order to do so, we turn to our static IO-PS analysis, introducing distance as well. It illustrates the change in average value chain complexity as well as the opportunity gain if all the remaining products within one particular product category would be attained and the total distance required to obtain that subsector.

Figure 5 visualizes the results. It displays the trade-off between (i) the sum of distances to the remaining products in a category, (ii) the change in average value chain complexity if an RCA is achieved for the remaining products within the category and (iii) the opportunity gain if an RCA is achieved for the remaining products within the category. The horizontal axis illustrates the sum of distances to the products in each product category with an RCA $<1$ and thus represents the expected difficulty required in order to obtain an RCA for the remaining products in the category. On the vertical axis one observes the change in average value chain complexity if all the remaining products within each product category would be attained, while the opportunity gain is represented by the size of the cross indicating each product category.

The higher the sum of distances - and hence the higher the expected difficulty - the higher the complexity and opportunity gain of product categories that can be attained. Figure 5 moreover indicates the complexity and opportunity gain Pareto sets of product categories. These are the sets of product categories for which - given the distance - it is not possible to attain a higher complexity or opportunity gain, respectively, given the sum of distances. Again - reassuringly - we notice that most of the time the sub-sectors with the highest 


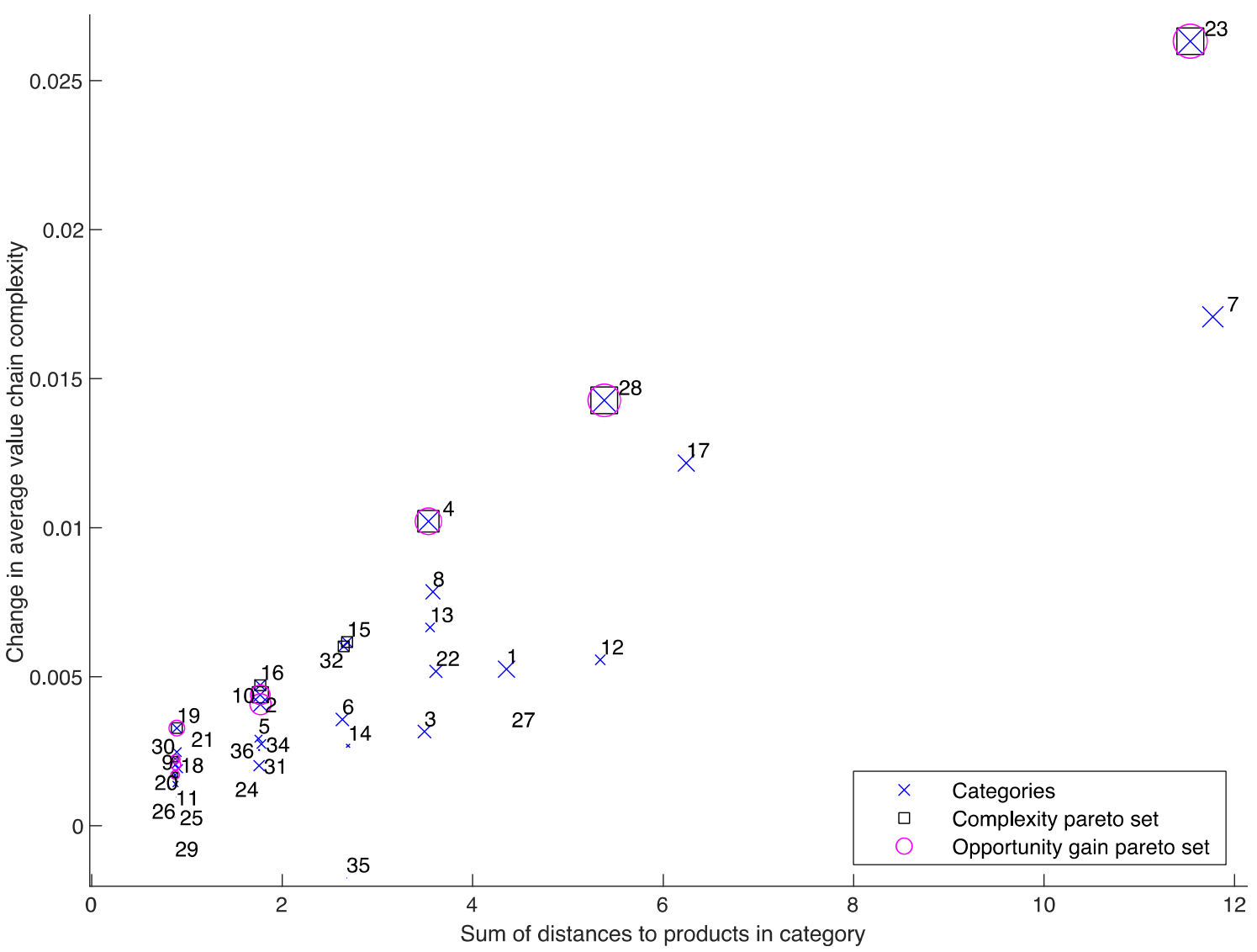

Figure 5 Complexity/opportunity gain/distances trade-off at product category level.

complexity are also those with the highest opportunity gain. For low to intermediate distances, subsectors 19 (Passenger Vehicle Bodies) and 4 (Passenger Vehicles) are good candidates from both complexity and opportunity gain point of view, while for larger distances, sectors 28 (Bearings) and 23 (Vehicle Parts) are unbeatable candidates. Thus far we have allowed the government to tackle one sub-sector at a time. The question, however, remains whether the government's strategy changes when they can subsequently tackle different sub-sectors. In order to answer this question, we resort to our dynamic analysis.

In the dynamic analysis, we again make a distinction between a shorter-term targeting strategy - focusing on maximizing complexity - and a longer-term strategy - focusing on maximizing opportunity gain. In our model, the distance is kept constant under different strategic 'investment' regimes. Within this confine, the government seeks to maximize either complexity or opportunity gain by attaining one or more product categories within the value chain that collectively constitute a cumulative distance smaller than or equal to the chosen distance constraint. Table 2 (maximizing complexity) and Table 3 (maximizing opportunity gain) contain the simulation results.

In each table, we determine (i) the (sequence of) targeted product categories for fixed distance constraints (and the distance use this sequence implies); (ii) the resultant average complexity of products within the value chain; and (iii) the opportunity gain within the product space. The distance constraints are derived from the frequency distribution of the average distances of products in each of the product categories in the automotive value chain to the rest of the product space. The maximum distance equals three ${ }^{8}$ times the distance to the 'furthest' product category.

Generally speaking, it comes as no surprise that the more ambitious the scenario (in terms of distance), the higher the complexity and opportunity gains are. There are, in other words, benefits to be expected from a policy that targets the automotive industry - and the more ambitious, the more benefit can be gained. Figures 6 and 7, however, 
Table 2 Model results for complexity maximizing case

\begin{tabular}{|c|c|c|c|c|c|c|}
\hline $\begin{array}{l}\text { Distance } \\
\text { constraint }\end{array}$ & $\begin{array}{l}\text { Distance } \\
\text { used }\end{array}$ & $\begin{array}{c}\text { Activity } \\
1\end{array}$ & $\begin{array}{c}\text { Activity } \\
2\end{array}$ & $\begin{array}{c}\text { Activity } \\
3\end{array}$ & $\begin{array}{c}\text { Average } \\
\text { complexity in } \\
\text { product space }\end{array}$ & $\begin{array}{c}\text { Opportunity } \\
\text { gain }\end{array}$ \\
\hline 1 & 0.9 & 19 & 0 & 0 & -0.338 & 0.34 \\
\hline 3 & 2.7 & 16 & 19 & 0 & -0.333 & 0.72 \\
\hline 5 & 4.4 & 4 & 19 & 0 & -0.328 & 1.32 \\
\hline 7 & 6.3 & 19 & 28 & 0 & -0.324 & 1.81 \\
\hline 9 & 8.9 & 4 & 28 & 0 & -0.317 & 2.44 \\
\hline 11 & 8.9 & 4 & 28 & 0 & -0.317 & 2.44 \\
\hline 13 & 12.4 & 19 & 23 & 0 & -0.312 & 1.95 \\
\hline 15 & 14.2 & 15 & 23 & 0 & -0.309 & 1.94 \\
\hline 17 & 16.9 & 23 & 28 & 0 & -0.301 & 3.03 \\
\hline 19 & 16.9 & 23 & 28 & 0 & -0.301 & 3.03 \\
\hline 21 & 19.4 & 4 & 1 & 23 & -0.300 & 3.32 \\
\hline 23 & 21.2 & 23 & 1 & 28 & -0.297 & 3.80 \\
\hline 25 & 24.7 & 4 & 23 & 28 & -0.292 & 3.94 \\
\hline 27 & 24.7 & 4 & 23 & 28 & -0.292 & 3.94 \\
\hline 29 & 27.4 & 17 & 23 & 28 & -0.290 & 3.73 \\
\hline 31 & 27.4 & 17 & 23 & 28 & -0.290 & 3.73 \\
\hline 33 & 33.0 & 7 & 23 & 28 & -0.286 & 4.17 \\
\hline 35 & 33.0 & 7 & 23 & 28 & -0.286 & 4.17 \\
\hline
\end{tabular}

illustrate that there are decreasing returns to targeting products within the automotive industry - both from the point of view of complexity (Fig. 6) and opportunity gain (Fig. 7). 'Blindly' increasing industry targeting therefore might not be the optimal policy route - the apparent return on investment should be balanced against the return that may be attained in other sectors of the economy as well. We therefore turn to the different product categories to analyze whether some are more promising than others hence building a case for a more differentiated approach as far as the automotive industrial policy in SA is concerned.

We start with a short-term perspective where the ultimate goal is to maximize complexity. As long as the policy is not very ambitious ${ }^{9}$, different combinations of two product categories are calculated as theoretically optimal for development. These include different combinations of product categories 19 (Passenger vehicle bodies), 4 (Passenger Vehicles), 15 (Meters and Counters), 16 (Engine Parts), and 28 (Bearings) for different distant constraints. For the scenarios where the distance constraint is increased above the value of 19 , different combinations of a total of three product categories becomes theoretically optimal. Product categories 23 (Vehicle Parts), 28 (Bearings), and 4 (Passenger Vehicles) remain good candidates, but 7 (Motorcycles and cycles) and 17 (Ignition/Starting Equipment) also enter the suggested industry combinations. Comparing our results to the complexity gain Pareto efficient sub-sectors from the static analysis in Fig. 5, we now observe both similar and new interesting sub-sectors to target. More in particular, for low distances, the importance of sub-sectors 15 and 16 is reconfirmed, while for higher distances sub-sectors 7 and 17 pop up. This is not surprising by looking at Fig. 5 because subsectors 15 and 16 are Pareto-efficient from a complexity point of view, while sub-sectors 7 and 17 have an extremely high complexity (runners-up of sub-sectors 23 and 28).

If the government were to take on a longer-term perspective, it should aim at a maximization of 
Table 3 Model results for opportunity gain maximizing case

\begin{tabular}{|c|c|c|c|c|c|c|}
\hline $\begin{array}{c}\text { Distance } \\
\text { constraint }\end{array}$ & $\begin{array}{c}\text { Distance } \\
\text { used }\end{array}$ & $\begin{array}{c}\text { Activity } \\
\mathbf{1}\end{array}$ & $\begin{array}{c}\text { Activity } \\
\mathbf{2}\end{array}$ & $\begin{array}{c}\text { Activity } \\
\mathbf{3}\end{array}$ & $\begin{array}{c}\text { Average } \\
\text { complexity in } \\
\text { product space }\end{array}$ & $\begin{array}{c}\text { Opportunity } \\
\text { gain }\end{array}$ \\
\hline 1 & 0.9 & 19 & 0 & 0 & -0.338 & 0.34 \\
\hline 3 & 2.7 & 2 & 19 & 0 & -0.334 & 0.96 \\
\hline 5 & 4.4 & 4 & 19 & 0 & -0.328 & 1.32 \\
\hline 7 & 6.3 & 19 & 28 & 0 & -0.324 & 1.81 \\
\hline 9 & 8.9 & 4 & 28 & 0 & -0.317 & 2.44 \\
\hline 11 & 10.6 & 19 & 1 & 28 & -0.319 & 2.60 \\
\hline 13 & 11.5 & 2 & 1 & 28 & -0.318 & 2.87 \\
\hline 15 & 13.3 & 4 & 1 & 28 & -0.312 & 3.22 \\
\hline 17 & 13.3 & 4 & 1 & 28 & -0.312 & 3.22 \\
\hline 19 & 13.3 & 4 & 1 & 28 & -0.312 & 3.22 \\
\hline 21 & 19.4 & 4 & 1 & 23 & -0.300 & 3.32 \\
\hline 23 & 21.2 & 23 & 1 & 28 & -0.297 & 3.80 \\
\hline 25 & 24.7 & 4 & 23 & 28 & -0.292 & 3.94 \\
\hline 27 & 24.7 & 4 & 23 & 28 & -0.292 & 3.94 \\
\hline 29 & 24.7 & 4 & 23 & 28 & -0.292 & 3.94 \\
\hline 31 & 24.7 & 4 & 23 & 28 & -0.292 & 3.94 \\
\hline 33 & 33.0 & 7 & 23 & 28 & -0.286 & 4.17 \\
\hline 35 & 33.0 & 7 & 23 & 28 & -0.286 & 4.17 \\
\hline & & & & & & \\
\hline
\end{tabular}

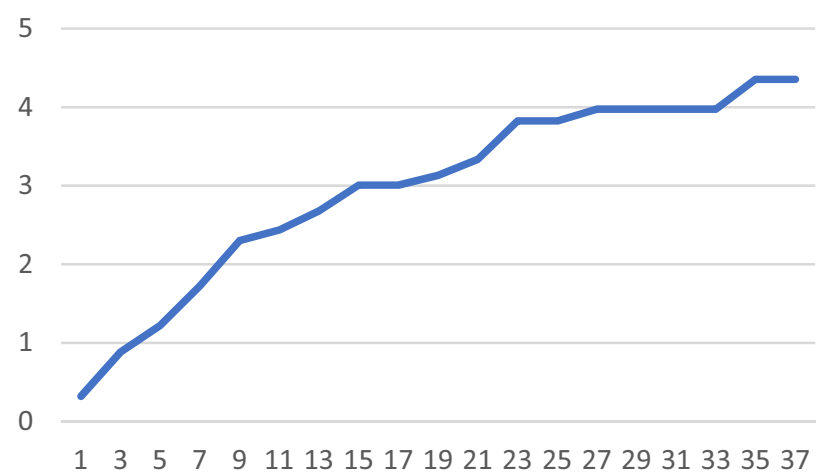

Figure 6 Total opportunity gain for different distance constraints in the SA automotive industry.

opportunity gain. As long as the policy is not very ambitious, different combinations of two product categories are calculated as theoretically optimal for development. Product categories 19 (Passenger vehicle bodies), 4 (Passenger Vehicles), 1 (Goods Transport Vehicles), 2 (Goods Transport Vehicles Warehousing), and 28 (Bearings) are recurring

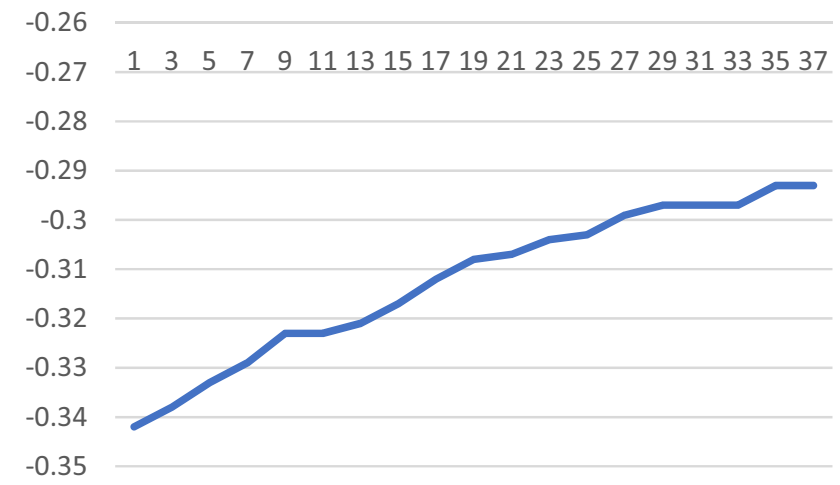

Figure 7 Average complexity of the products within South Africa's product space after attaining an RCA for all products within the categories targeted under different distance constraints.

categories for different distant constraints. For the scenarios where the distance constraint is increased above the value of 9, different combinations of a total of three product categories becomes theoretically optimal. Product categories 4 (Passenger 
Vehicles) and 28 (Bearings) remain good candidates but 23 (Vehicle parts) and 7 (Motorcycles and cycles) also enter the suggested industry combinations. The longer-term view thus calls for more diversification by tackling more industries, while the shorter-term view prioritizes the development of fewer, but more complex sub-sectors that are located at further distances.

Compared to the static analysis, for low distances the dynamic analysis illustrates the importance of sub-sectors 1 and 2 as well, while for larger distances the dynamic analysis also suggests tackling sector 7. Sub-sector 2 is Pareto-efficient, but the other two sectors would not initially have been targeted in the static analysis, given the fact that they were not Pareto-maximizing. It therefore becomes obvious that taking a dynamic time frame into account, new, non-Pareto-efficient sub-sectors become interesting as well.

\section{Discussion of Implication of Results}

More recently, a number of authors have been investigating theoretically optimal development routes in the product space. In particular, Alshamsi, Pinheiro, and Hidalgo (2018) show, by means of a theoretical experiment, that a mixed strategy that focusses on the products that have the lowest distance value and products that have the largest number of links to existing products ${ }^{10}$ would be the theoretically optimally targeting strategy if the goal is to diversify into all products within the minimum time period. On the other hand, Pinheiro, Alshamsi, Hartmann, Boschma, and Hidalgo (2018) analyze the economic diversification paths of 93 countries over a 40-year period. They find that countries enter related products in approximately 92.8\% of the observations. However, when countries do enter unrelated products, this supports increased economic growth ${ }^{11}$. Furthermore, they show that countries are more likely to enter such unrelated activities at intermediate levels of economic development.

These studies thus seem to suggest that countries like South Africa that are caught in the "(upper)middle-income-trap" might be well advised to focus on high-impact activities close to their current production structures (small distance), but that this should also be combined with the targeting of high-opportunity-gain activities that might be further from their current production structure (higher distance). For our particular case study, when the optimization results for both the complexity maximizing and opportunity gain strategies are viewed together, it appears to be advisable to diversify the general automotive industrial policy and specifically target those product sub-sectors that will maximize both complexity and opportunity gain and provide a mix of distance values. Thus, passenger vehicle bodies, passenger vehicles and bearings, seem to be good targets that will improve both opportunity gain and complexity at small-tomoderate distances. On the other hand, vehicle parts and motorcycles and cycles seem to hold potential at higher distances to also increase both metrics of interest and could potentially unlock significant new capabilities for the country. However, the activities with the higher distance values should be carefully evaluated to ensure an appreciation of the factors that might have contributed to their "distance" and hence whether it would be feasible to target them at all. This finding can be linked to the decreasing returns in targeting products both from the point of view of complexity as well as opportunity gain observed in Figs. 6 and 7. Although increasing the budget overall might indeed lead to positive returns but at a diminishing rate, it could still be worth the investment if this targeted investment increases complexity significantly and/or unlocks new opportunities for the country elsewhere in the product space. Further case studies for the different selected product categories are therefore in a second stage needed in order to provide a better insight in the optimal ranking of these categories - given both the required investments as well as their feasibility. For instance, a global value chain analysis such as the one by Sturgeon and Biesebroeck (2011) performed for the automotive industry in China, India, and Mexico could provide valuable additional insights regarding the local dynamics and structure of the industry that could be vital for successful policy making.

The main advantage of the IO-PS approach in a first stage is indeed its ability to very rapidly generate an overview of those product categories within the automotive value chain that are worthwhile targeting both from a complexity and an opportunity gain point of view. More in particular, the IO-PS approach illustrates - both in a static and dynamic way - the trade-off between distance, complexity, and opportunity gain for one particular industry. Its contribution is therefore that it states on which parts of the value chain the industrial policy should focus preferably. Although the IO-PS provides some valuable insight to evaluate broad-based policies, it has more potential to evaluate and direct targeted policies. 
Our analysis has also revealed that there might be various factors affecting RCA values. In particular, the very large fluctuation of the value of a small number of products in the export basket (as is often experienced by mineral depended countries) can impact the RCA value calculated for all other products and thereby significantly affect the number of a country's products that are seen to be exported with an RCA and thus also its complexity value. On the one hand, this highlights the care with which product space-related metrics must be assessed and how such analyses must be applied with an appreciation of the limits of the methodology. On the other hand, it might also highlight the potentially distorting effects on economies when the mining sector and similar single commodity industries grow at a rate outpacing other sectors. Specialization and reliance on only a limited number of products for economic growth and foreign exchange is already widely acknowledged to potentially being harmful to the prospects of the wider economy in the longer run (Fitjar \& Timmermans, 2019).

\section{CONCLUSION}

We critically investigated the ability of the product space, and the input-output product space (IO-PS) in particular, to support the evaluation of government policies in a given value chain over an extended time period. In particular, we performed a cross-sectional analysis of the input-output product space results for the South African automotive value chain. This enabled a historical evaluation of the Motor Industry Development Programme (MIDP) and the Automotive Production and Development Programme (APDP) that the South African government have implemented. In particular, we first evaluated whether the implemented policies have led to the growth of the targeted industries and were thus able to tentatively confirm the (partial) success that these broad-based policies have achieved. In a next step, we analyzed whether it would be reasonable to diversify the broad-based automotive policy to target product categories that seem to hold more specific potential for economic growth.

Our results suggest that there are specific subsectors within the industry that could be developed and that should support short- and long-term economic growth. Hence, it may be reasonable to diversify the broad-based automotive policy to focus on the underdeveloped parts of these particular sub-sectors. These include sub-sectors that appear to be well related to the current capabilities within the country, such as bearings, passenger vehicle bodies and passenger vehicles, and product categories that might not align so closely with current capabilities in the country, but could support the development of capabilities that might support the development of other high potential products in the future such as vehicle parts and motorcycles and cycles. Our cross-sectional design also highlights some of the nuances that should be considered when analyzing RCA as a metric of industry performance. In particular, the RCA values of any one industry are intricately linked to the export performance of all other industries. This might become a concern when a small number of products make up a substantial part of the export basket and dramatically change in value over time. This is of particular relevance to a large number of developing countries that export products such as minerals or oil that make up a large part of these countries' exports and can rapidly distort the export basket of such countries.

The main advantage of the IO-PS approach is that it allows for an immediate overview of those product categories within the automotive value chain that are worth further investigation. However, one research limitation is that the analyses are based on data for 1 year and therefore do not consider the trends for any particular industry. Machine learning approaches provide an interesting avenue for future research on this account. Secondly, the IO-PS approach is mainly appropriate to assess targeted (industrial) policy and less so to address the effectiveness of broad-based policies. Finally, the PS metrics in this paper focus on economic growth as such - without necessarily taking into account whether this growth is sustainable or not. In order to take the crucial sustainability aspects into account as well, another avenue for future research is to include inequality metrics (Hartmann, Guevara, Jara-Figueroa, Aristarán, \& Hidalgo, 2017) or new approaches that provide a first filtering of products based on their ability to contribute towards green development (Fraccascia, Giannoccaro, \& Albino, 2018; Mealy \& Teytelboym, 2020).

\section{ACKNOWLEDGEMENTS}

The financial support of the VLIR-UOS South Initiative 2020 'Improving Industrial Policy Intervention in 
South Africa' (SI-2020-01-88) is gratefully acknowledged. We thank Ari Van Assche as well as three anonymous reviewers for their constructive comments on the paper.

\section{NOTES}

${ }^{1}$ The Washington consensus (Williamson, 1990) identified the market as a universally efficient mechanism to allocate scarce resources and promote economic growth, while the post-Washington Consensus recognized cases in which government market interventions can play a positive role (Stiglitz, 1998).

${ }^{2}$ We use 'product category' and 'sub-sector' interchangeably throughout the paper.

${ }^{3}$ Depending on the data source.

${ }^{4}$ http://www.thedti.gov.za/industrial_development/ sectors.jsp.

${ }^{5}$ Currently $38.7 \%$.

${ }^{6}$ Figures A.1 and A.2 in the Appendix illustrate respectively the change in the ratio of South African over world exports and the RCA values for the different product categories from 1995 to 2017. The years 1995 and 2017 are clearly no outliers.

\section{REFERENCES}

Abdon, A., \& Felipe, J. 2011. The product space: What does it say about the opportunities for growth and structural transformation of Sub-Saharan Africa?. No. 670. SSRN Electronic Journal. Accessed Sept 7, 2017, from https://papers.ssrn.com/sol3/ papers.cfm?abstract_id=1846734.

Alshamsi, A., Pinheiro, F. L., \& Hidalgo, C. A. 2018. Optimal diversification strategies in the networks of related products and of related research areas. Nature Communications, 9(1): 1328.

Balassa, B. 1965. Trade liberalisation and "revealed" comparative advantage. The Manchester School, 33(2): 99-123.

Bam, W., \& De Bruyne, K. 2017. Location policy and downstream mineral processing: A research agenda. Extractive Industries and Society, 4(3): 443-447.

Bam, W., \& De Bruyne, K. 2019. Improving industrial policy intervention: The case of steel in South Africa. Journal of Development Studies, 55(11): 2460-2475.

Barnes, J., Black, A., Comrie, D., \& Hartogh, T. 2018. Geared for growth: South Africa's automotive industry masterplan to 2035: A report of the South African Automotive Masterplan Project.

Barnes, J., \& Morris, M. 2008. Staying alive in the global automotive industry: What can developing economies learn from South Africa about linking into global automotive value chains? European Journal of Development Research, 20(1): 3155.

Black, A. \& Bhanisi, S. 2007. The SA Automotive industry in a globalising world - What has happened to imports? Trade \& Industry Monitor, 38: 131-152.

Cheng, Y., Farooq, S., \& Johansen, J. 2015. International manufacturing network: Past, present, and future. International Journal of Operations \& Production Management, 35(3): 392-429.
${ }^{7}$ For complexity and opportunity gain, higher values are deemed more desirable; for distance, lower values are.

${ }^{8}$ Ideally, no restriction should be placed on the number of product categories included in the analysis and distance should act as the only restriction. However, the number of categories was artificially limited for the practical consideration of computer running time required as it increases exponentially when an additional industry is included. The foresight of three industries was deemed to be sufficient, as various other aspects of the product space may also have changed in the time it takes to acquire three industries, justifying a rerun of the simulation.

${ }^{9}$ Implying only a small distance needs to be overcome and/or a small investment needs to be made.

${ }^{10}$ Though not necessarily a low distance, due to the product potentially having links to a very large number of other products.

${ }^{11}$ In fact, economic growth seems to increase by $0.5 \%$ per annum compared to otherwise similar countries.

Cimoli, M., Dosi, D., \& Stiglitz, J. 2009. Industrial policy and development: The political economy of capabilities accumulation. New York, NY: Oxford University Press.

Coe, N. M., \& Yeung, H. W. 2019. Global production networks: Mapping recent conceptual developments. Journal of Economic Geography, 19(4): 775-801.

Department: Trade and Industry. 2014. The DTI Budget Vote Address delivered by Dr Rob Davies, Minister of Trade and Industry, 22 July 2014.

Dunning, J. H. 1998. Location and the multinational enterprise: A neglected factor? Journal of International Business Studies, 29(1): 45-66.

Felipe, J., Kumar, U., Abdon, A., \& Bacate, M. 2012. Product complexity and economic development. Structural Change and Economic Dynamics, 23(1): 36-68.

Fitjar, R. D., \& Timmermans, B. 2019. Relatedness and the resource curse: Is there a liability of relatedness? Economic Geography, 95(3): 231-255.

Fortunato, P., Razo, C., \& Vrolijk, C. 2015. Operationalizing the product space: a road map to export diversification. United Nations Conference on Trade and Development (UNCTAD), (219).

Fraccascia, L., Giannoccaro, I., \& Albino, V. 2018. Green product development: What does the country product space imply? Journal of Cleaner Production, 170: 1076-1088.

Gereffi, G. 2014. Global value chains in a post-Washington Consensus world. Review of International Political Economy, 21(1): 9-37.

Gereffi, G., \& Lee, J. 2014. Economic and social upgrading in global value chains and industrial clusters: Why governance matters. Journal of Business Ethics. https://doi.org/10.1007/ s10551-014-2373-7. 
Hartmann, D., Bezerra, M., Lodolo, B., \& Pinheiro, F. L. 2019. International trade, development traps, and the core-periphery structure of income inequality. SSRN Electronic Journal. https://doi.org/10.2139/ssrn.3312097.

Hartmann, D., Guevara, M. R., Jara-Figueroa, C., Aristarán, M., \& Hidalgo, C. A. 2017. Linking economic complexity, institutions, and income inequality. World Development, 93: 7593.

Hausmann, R., Hidalgo, C. A., Bustos, S., Coscia, M., Chung, S., \& Jimenez, J., et al. 2011. The atlas of economic complexity: Mapping paths to prosperity.

Hausmann, R., \& Klinger, B. 2006. Structural transformation and patterns of comparative advantage in the product space. No. RWP06-041. KSG Working Paper.

Hausmann, R., \& Klinger, B. 2008. South Africa's export predicament. Economics of Transition, 16(4): 609-637.

Hausmann, R., \& Rodrik, D. 2006. Doomed to choose: Industrial policy as predicament. Center for International Development Blue Sky Conference, Sept. 9 2006, Cambridge, MA.

Hidalgo, C. A., \& Hausmann, R. 2009. The building blocks of economic complexity. Proceedings of the National Academy of Sciences of the United States of America, 106(26): 1057010575.

Hidalgo, C. A., Klinger, B., Barabasi, A.-L., \& Hausmann, R. 2007. The product space conditions the development of nations. Science, 317(5837): 482-487.

Horner, R. 2017. Beyond facilitator? State roles in global value chains and global production networks. Geography Compass, 11(2): 1-13.

Jankowska, A., Nagengast, A., \& Perea, J. 2012. The product space and the middle-income trap: Comparing Asian and Latin American Experiences. No. 311.

Lavopa, A., \& Szirmai, A. 2018. Structural modernisation and development traps. An empirical approach. World Development, 112: 59-73.
Li, F., Frederick, S., \& Gereffi, G. 2019. E-commerce and industrial upgrading in the Chinese apparel value chain. Journal of Contemporary Asia, 49(1): 24-53.

Marais, M., \& Bam, W. 2019. Developmental potential of the aerospace industry: The case of South Africa. 2019 IEEE International Conference on Engineering, Technology and Innovation (ICE/ITMC): 1-9. IEEE.

Mealy, P., \& Teytelboym, A. 2020. Economic complexity and the green economy. Research Policy, (In Press).

OEC. 2019. South Africa Country profile.

OEC. 2020a. Data sources.

OEC. 2020b. What does South Africa export?.

Pinheiro, F. L., Alshamsi, A., Hartmann, D., Boschma, R., \& Hidalgo, C. A. 2018. Shooting high or low: Do countries benefit from entering unrelated activities?. No. 1807.

Spring, M., Hughes, A., Mason, K., \& McCaffrey, P. 2017. Creating the competitive edge: A new relationship between operations management and industrial policy. Journal of Operations Management, 49-51: 6-19.

Stiglitz, J. E. 1998. More Instruments and Broader Goals: moving Towards the Post-Washington Consensus. Helsinki: United Nations University. World Institute for Development Economics Research.

Sturgeon, T. J., \& Van Biesebroeck, J. 2011. Global value chains in the automotive industry: An enhanced role for developing countries? International Journal of Technological Learning, Innovation and Development, 4(1-3): 181-205.

Vardhana Singh, H., Gupta, K., Sudan, R., \& Singh, R. 2018. Product space analysis and industrial policy: Identifying potential products for India's export expansion \& diversification. Brookings India, 125-139.

World Bank. 2019. World Bank Atlas Method. World Bank, https://datahelpdesk.worldbank.org/knowledgebase/articles/ 906519.

\section{APPENDIX}

Figure A.1 illustrates the change in the ratio of South African over world exports for the different product categories from 1995 to 2017. Figure A.2 plots the RCA values for the different product categories from 1995 to 2017.

As is obvious from Figure A.1, on average the ratio of South African exports over world exports increases for most exports throughout the years 1995-2017 - except for a few sectors. This also implies that 1995 and 2017 are not considered outliers and we can safely compare these 2 years in our analysis. Figure A.2 paints a less positive picture overall and illustrates that throughout the years for some product categories RCA has increased while for other product categories RCA has decreased. The years 1995 and 2017 however are again no outliers. 
Figure A.1 Ratio South African exports/world exports for all product categories 1995-2017.

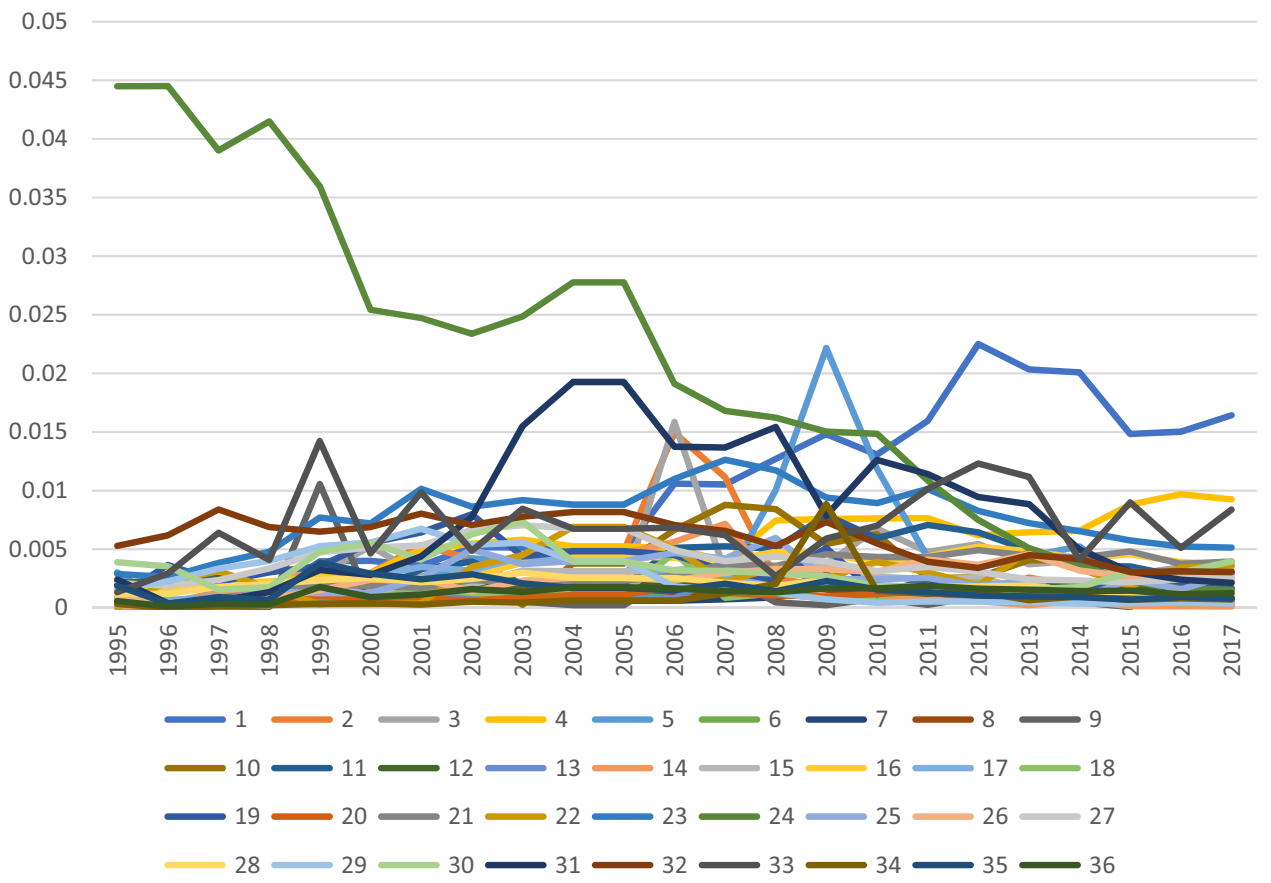

Figure A.2 RCA for all product categories 1995-2017.

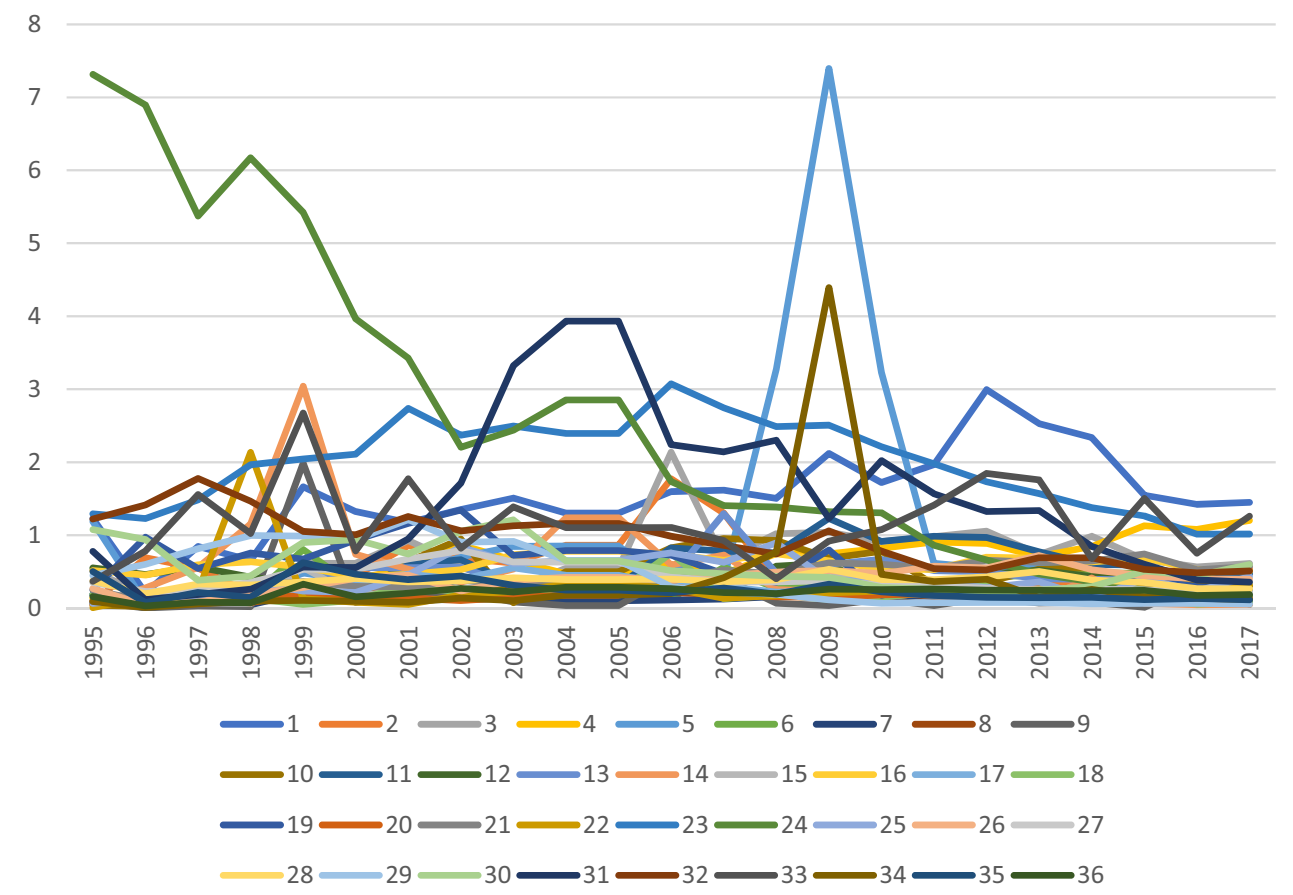

\section{ABOUT THE AUTHORS}

Wouter G. Bam is a Senior Lecturer at the Department of Industrial Engineering at Stellenbosch University. His research deals with industrial policymaking, inclusive innovation, and decision-support systems.
Karolien De Bruyne is Assistant Professor at the Faculty of Economics and Business of KU Leuven and Associate Professor Extraordinary at the Department of Industrial Engineering at Stellenbosch University. Her research deals with international trade and global value chains, development 
economics, labor economics, and location decisions of firms.

Mare Laing is a full-time master's student at the Department of Industrial Engineering at Stellenbosch University. Her research focusses on industrial policymaking in the South African automotive industry.

Open Access This article is licensed under a Creative Commons Attribution 4.0 International License, which permits use, sharing, adaptation, distribution and reproduction in any medium or format, as long as you give appropriate credit to the original author(s) and the source, provide a link to the Creative Commons licence, and indicate if changes were made. The images or other third party material in this article are included in the article's Creative Commons licence, unless indicated otherwise in a credit line to the material. If material is not included in the article's Creative Commons licence and your intended use is not permitted by statutory regulation or exceeds the permitted use, you will need to obtain permission directly from the copyright holder. To view a copy of this licence, visit http://creativecommons.org/licenses/by/4.0/.

Publisher's Note Springer Nature remains neutral with regard to jurisdictional claims in published maps and institutional affiliations.

Accepted by Ari Van Assche, Deputy Editor, 12 October 2020. This article has been with the authors for three revisions. 